Pre-test Set

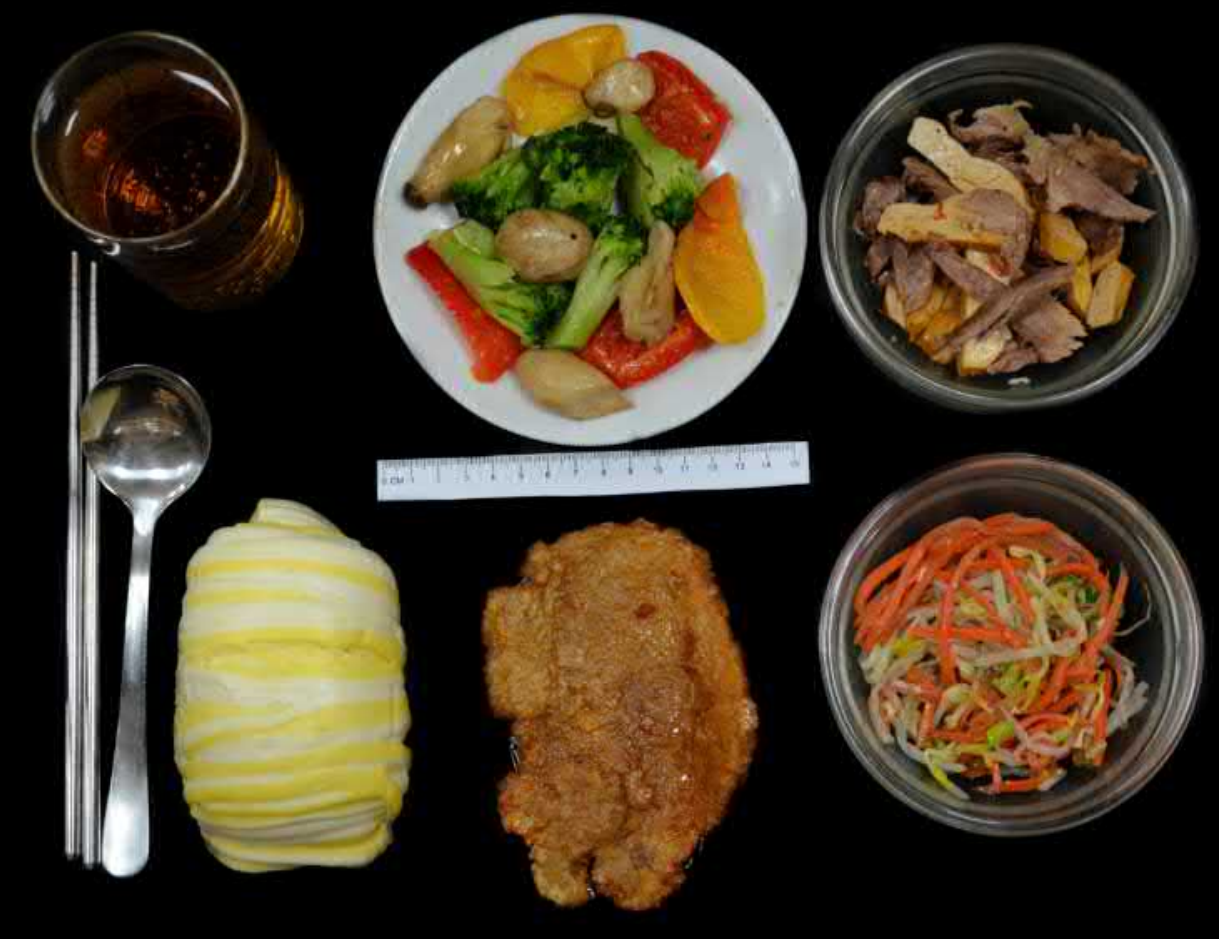




\section{Breakfast Set}

\section{5 豆漿}

Soymilk

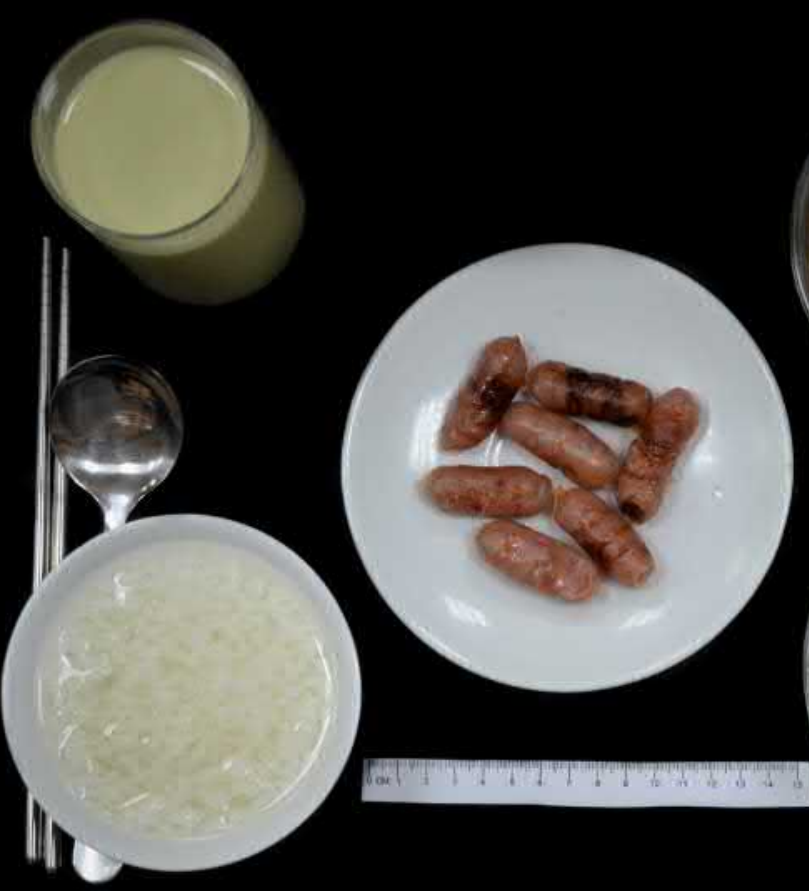

\section{1 煮稀飯}

\section{4 花豆檪麵腸}

Stewed wheat gluten with peanuts

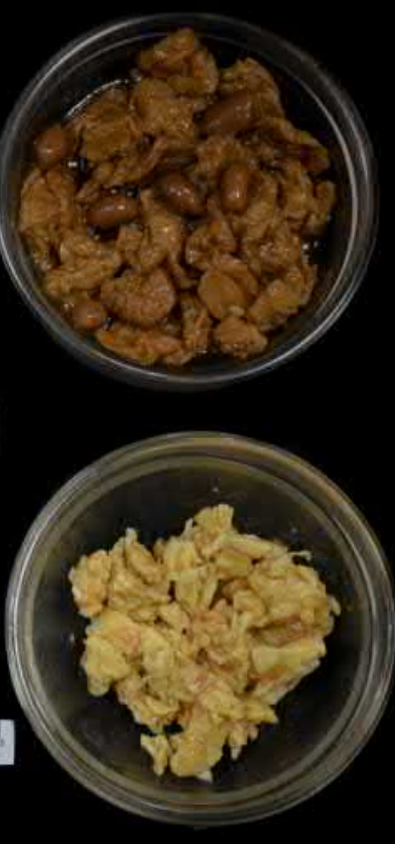

3 炒雞蛋

Stir-fried chicken egg 


\section{Lunch Set}

6 綠茶 5 培根木耳炒高麗菜 4 豆腐炒四季豆

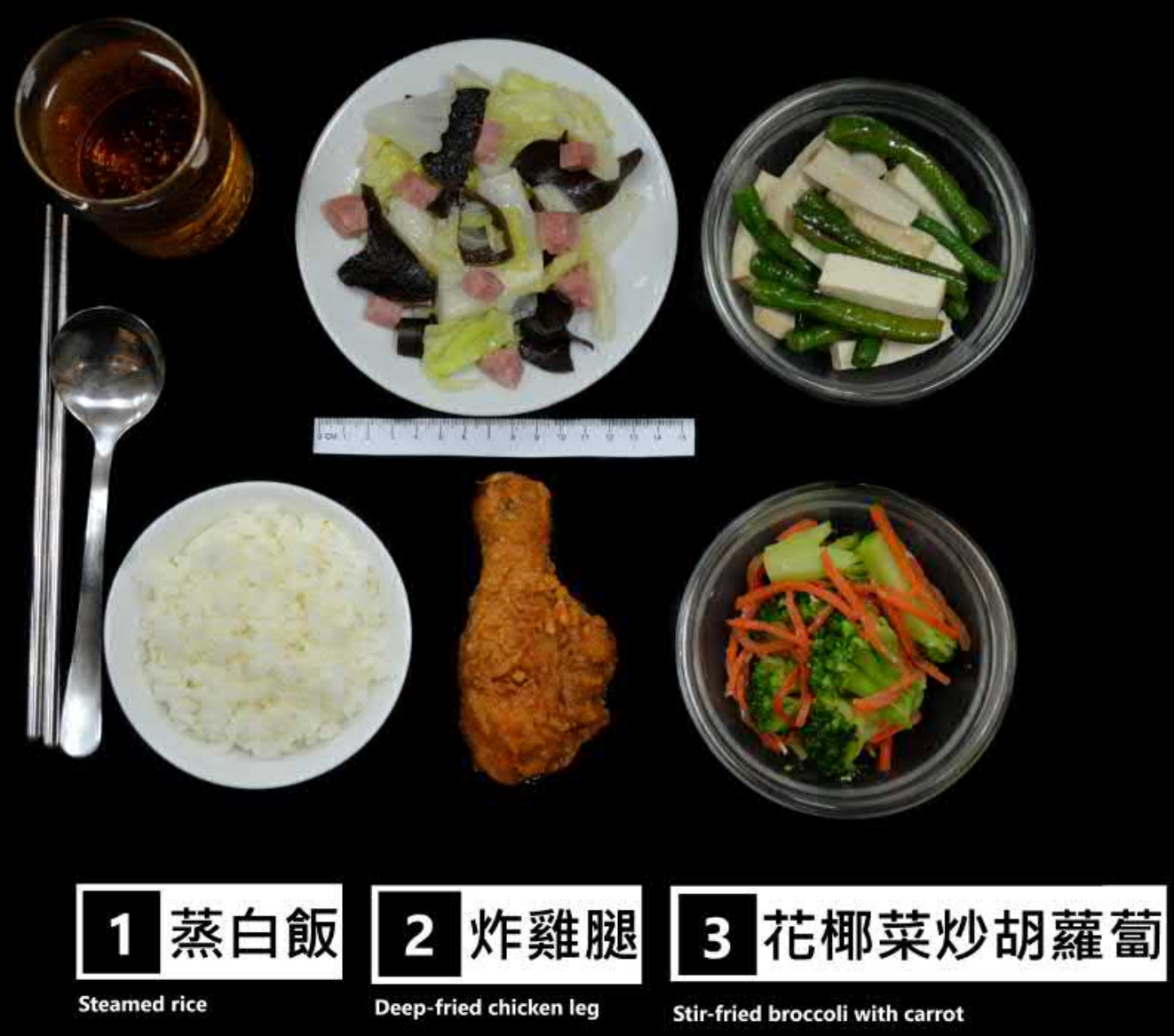




\section{Dinner Set}

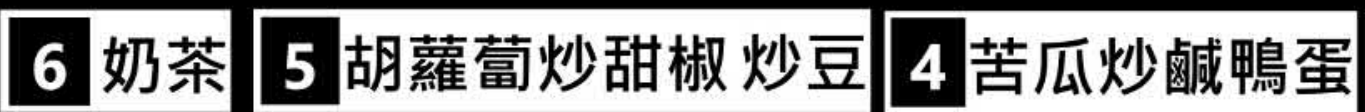 \\ Milk tea \\ Stir-fried dry bean curd with bell pepper an \\ Stir-fried bitter melon with salted duck egg}
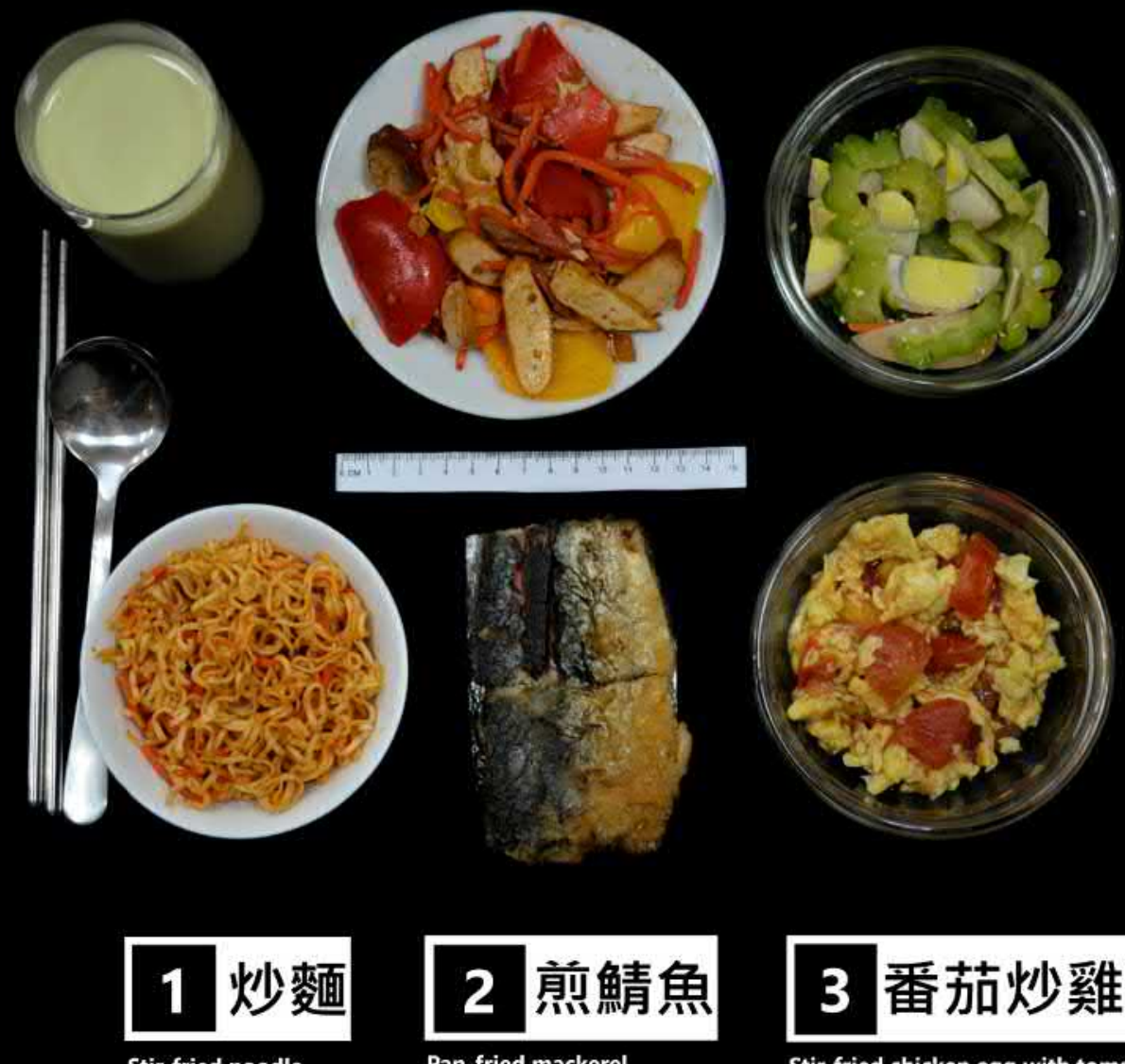

Pan-fried mackerel
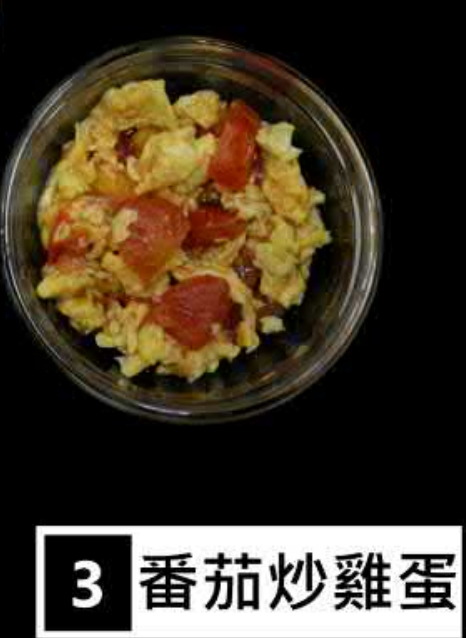

Stir-fried chicken egg with tomato 